\title{
Als je mensen leert kennen, ga je van dieren houden: de mogelijkheden van diertherapie in detentie*
}

Janine Janssen **

'Er is iets in de onbaatzuchtige en zelfopofferende liefde van een redeloos dier dat direct het hart treft van wie meermalen in de gelegenheid is geweest de armzalige en vluchtige trouw te toetsen van slechts een Mens.' Edgar Allen Poe (2000: 493).

\section{Inleiding}

Over de vraag waarom mensen huisdieren houden, doen verschillende verhalen de ronde. Sommigen menen dat dierenliefhebbers zo teleurgesteld zijn in hun contacten met medemensen, dat zij de voorkeur geven aan het gezelschap van dieren. Anderen beweren dat met name alleenstaanden en ouden van dagen aangewezen zijn op huisdieren omdat zij weinig andere sociale contacten hebben. Weer anderen menen dat vooral dominante mensen, die in hun sociale contacten geen vorm kunnen geven aan hun dominante neigingen, vervolgens 'overstappen' op dieren. Uit wetenschappelijk onderzoek blijkt echter dat deze opvattingen op misverstanden berusten: het is moeilijk om verschillen aan te geven tussen houders van dieren en andere mensen. Bovendien blijkt in de praktijk dat de meeste huisdieren niet door alleenstaanden worden gehouden, maar met name in gezinsverband. De vraag waarom mensen huisdieren houden is dus niet eenduidig te beantwoorden. (Raes, 2001: 248).

*Een bewerking van deze tekst zal in Sancties verschijnen.

**Mevrouw Janssen werkte als onderzoeker bij de vakgroep Strafrecht en Criminologie toen zij dit stuk schreef en is momenteel werkzaam als senior onderzoeker bij de politie Haaglanden. 
Hoe het ook zij, feit is dat in de westerse wereld het houden van huisdieren uitermate populair is: halverwege de jaren negentig werd Nederland alleen al bevolkt door ongeveer 1,4 miljoen honden en 2,1 miljoen katten (Mombarg, 2000: 285). ${ }^{1}$

We komen huisdieren echter niet alleen in reguliere huishoudens tegen, maar ook steeds meer in instellingen, zoals bejaardentehuizen, ziekenhuizen, maar ook in penitentiaire inrichtingen. In dergelijke instellingen worden dieren vaak om therapeutische redenen ingezet. In dit artikel sta ik stil bij deze therapeutische aspecten van de aanwezigheid van huisdieren in penitentiaire instellingen. Allereerst wordt kort in gegaan op de achtergronden van diertherapie. Vervolgens wordt nagegaan welke gunstige effecten de aanwezigheid van dieren in penitentiaire inrichtingen met zich meebrengt. Een andere belangrijke vraag is verder aan welke voorwaarden voldaan moet worden om de aanwezigheid van dieren in detentie, voor zowel mens als dier tot een succes te maken. De tekst wordt afgesloten met enkele kritische kant-tekeningen ten aanzien van de plaatsing van dieren in penitentiaire inrichtingen.

\section{Wat is dierentherapie?}

De term 'pet therapy' ${ }^{2}$ werd voor het eerst gebruikt in 1969 door de Amerikaanse kinderpsychiater Boris Levinson. Levinson doelde hiermee op het inzetten van dieren bij de behandeling van psychiatrische stoornissen. Hem viel op dat zijn patiëntjes die moeite hadden om contacten met andere mensen te leggen, vaak wel enthousiast op zijn hond Jingles reageerden. De kinderen betrokken de hond snel in spelletjes en in hun fantasiewereld, waarbij ze aanvankelijk de aanwezigheid van de psychiater negeerden. Levinson slaagde er echter in om stap voor stap toch bij de interactie tussen het kind en de hond betrokken te raken. De hond maakte zich dus verdienstelijk door in eerste instantie het ijs te breken en de gevoelens van vijandigheid bij het kind te verminderen of weg te nemen en in tweede instantie maakte de hond communicatie tussen het kind en de psychiater mogelijk. De eerste publicaties van Levinson over dierentherapie - gebaseerd op de ervaringen met zijn

\footnotetext{
${ }^{1}$ Door hun grote aantallen zijn huisdieren ook een belangrijke economische factor geworden: per jaar besteedt een Nederlands huishouden ongeveer driehonderd gulden aan hun huisdier(en) (Mombarg, 2000: 285).

${ }^{2}$ In deze tekst wordt 'pet therapie' vertaald als 'dierentherapie'.
} 
hond in zijn praktijk - werden sceptisch ontvangen. ${ }^{3}$ Zijn grote verdienste was echter dat hij de eerste was die het onderwerp serieus en wetenschappelijk benaderde (Serpell, 1986: 73-76).

In de jaren zeventig en tachtig volgden verschillende onderzoeken waarin werd getracht de ideeën van Levinson te toetsen. Het merendeel van deze studies richtte zich op de invloed van huisdieren op mensen met psychische en/of psychiatrische stoornissen, gehandicapten en oudere mensen. ${ }^{4}$ Kenmerkend was verder dat in deze studies hoofdzakelijk aandacht werd besteed aan mensen die in instellingen leven. Ter illustratie volgt hier een kort en niet volledig overzicht van enkele bekende onderzoeksprojecten. In een Amerikaans longitudinaal onderzoek is een vergelijking gemaakt tussen bejaarden met en zonder katten. Binnen een jaar werden er al interessante verschillen gevonden: oudere mensen met katten bleken minder last te hebben van gevoelens van eenzaamheid, angst en depressie. Daarnaast werd aangetoond dat de kattenbezitters minder medicijnen gebruikten en een lagere bloeddruk hadden. Vergelijkbare resultaten zijn ook bij eigenaren van honden gevonden. Een ander onderzoek -eveneens in de Verenigde Staten uitgevoerd - laat zien dat eigenaren van huisdieren die naar aanleiding van hartziekten, zoals hartinfarcten, in het ziekenhuis waren opgenomen, een grotere kans op overleven hadden, dan patiënten zonder huisdieren. De aanwezigheid van een huisdier zou zelfs een beter voorspeller van de kans op overleven zijn dan de aanwezigheid van een partner of familie. Er is niet alleen onderzoek gedaan naar de invloed van dieren op het fysieke welbevinden van mensen. In de onderzoeksliteratuur is ook veel aandacht besteed aan de invloed van dieren op de geestelijke gezondheid van mensen. Zo zijn er diverse onderzoeken gewijd aan processen van rouwverwerking na het verlies van de partner. Huisdieren zouden na de dood van een geliefd persoon bij de achtergeblevene het gevoel van isolement en depressie doen afnemen. Tevens wordt in deze onderzoeken geconcludeerd dat de algemene gezondheidstoestand en het medicatiegebruik van rouwenden met huisdieren

${ }^{3}$ Het idee dat dieren een gunstige uitwerking hebben op de gezondheid van mensen, stamt echter al uit de klassieke oudheid. Zie voor een overzicht: Serpell, 1986: 7475.

${ }^{4}$ De eerste onderzoeken op dit terrein waren hoofdzakelijk gericht op oudere mensen, die immers relatief meer een beroep doen op de gezondheidszorg (Franklin, 1999: 101). 
gunstiger is in vergelijking met dat van rouwenden zonder dieren (Sheldrake, 1999: 73-74).

Over het algemeen worden aan de meeste onderzoeken, zoals hierboven beschreven, positieve conclusies ten aanzien van de dierentherapie verbonden. Op basis van deze onderzoeken blijft het echter moeilijk - om methodologische redenen - om harde conclusies te trekken. Uit de literatuur wordt echter wel duidelijk dat dierentherapie vooral aanslaat bij mensen die zich verworpen of aan de kant gezet voelen. Verder is er voldoende 'bewijs' om te stellen dat dieren mensen kunnen helpen zich te ontspannen en dat dieren het 'ijs kunnen breken' zodat mensen in vreemde of ongewende situaties - zoals een therapeutische setting - zich meer op hun gemak voelen. (Serpell, 1986: 79-83).

Dierentherapie wordt vooral binnen instellingen toegepast, zoals bejaardentehuizen $^{5}$ en psychiatrische inrichtingen. In de Verenigde Staten wordt sinds de jaren zeventig geëxperimenteerd in penitentiaire inrichtingen. Helaas wordt aan de toepassing van dierentherapie in penitentiaire inrichtingen in de literatuur relatief weinig aandacht besteed. In de volgende paragraaf wordt verder ingegaan op eventuele gunstige effecten van de aanwezigheid van dieren in penitentiaire inrichtingen. Daarbij wordt met name gebruik gemaakt van voorbeelden uit het Nederlandse en het Amerikaanse gevangeniswezen. ${ }^{6}$

\section{Gunstige effecten van de aanwezigheid van dieren in penitentiaire in- richtingen}

Door directies van instellingen zoals bejaardentehuizen of penitentiaire inrichtingen worden vaak verschillende nadelen genoemd, die verbonden zijn aan de aanwezigheid van dieren in de instelling: in de eerste plaats wordt vaak gewezen op hygiëne ${ }^{7}$ en op de extra belasting voor het personeel die de verzorging van dieren met zich mee brengt. In deze paragraaf wordt niet verder ingaan op deze aspecten, maar uitsluitend gekeken naar de positieve invloed die de aanwezigheid van dieren op instellingsbewoners kan hebben:

${ }^{5}$ Zie voor de beschrijving van een dergelijk project in België: Bouckaert, 2001.

${ }^{6}$ Ter illustratie wordt hier slechts een aantal voorbeelden genoemd. Voor een uitgebreider overzicht, zie: Janssen B, 2000.

${ }^{7}$ Denk in dit verband bijvoorbeeld aan het uitbreken van de vogelpest in de jaren tachtig. Naar aanleiding van deze epidemie werd in veel Nederlandse penitentiaire inrichtingen het houden van vogels streng beperkt of verboden. 
namelijk een verbetering van de psychische conditie van de bewoners en van de sfeer in de instelling.

Verbetering van de psychische conditie van gedetineerden

In de vorige paragraaf is aangegeven dat uit de literatuur blijkt dat van de aanwezigheid van huisdieren een rustgevende werking uitgaat en dat dierentherapie vooral aanslaat bij mensen die zich verworpen voelen. Hier gaan we daar iets dieper op in. Allereerst moeten we terug naar de in de inleiding gestelde vraag: waarom houden mensen huisdieren. Het is niet eenvoudig om die vraag te beantwoorden. Uit praktisch elk onderzoek dat ooit naar de relatie tussen mensen en hun huisdieren is gehouden, blijkt echter wel dat eigenaren doorgaans het hebben van gezelschap of vriendschap als de belangrijkste reden opgeven voor het in huis halen van een dier (Serpell, 1996: 106-107). Opvallend is verder dat houders van huisdieren er vaak toe neigen dieren menselijke eigenschappen toe te dichten. Alleen al door het dier een naam te geven, wordt het tot een subject gemaakt en krijgt het een belangrijke rol in de eigen leefwereld. ${ }^{8}$ Eigenaren menen gevoelens van verdriet, vreugde, dankbaarheid, jaloezie, boosheid, vriendschap, aanhankelijkheid en dergelijke bij hun huisdier te kunnen herkennen (Raes, 2001: 251). ${ }^{9}$ Dit herkennen van menselijke emoties in dieren wordt vergemakkelijkt door het feit dat dieren niet kunnen praten (Sheldrake, 1999: 80). Hierdoor wordt het mensen gemakkelijk gemaakt om in dieren te herkennen waar ze zelf op dat

${ }^{8}$ Interessant in dit verband is het onderzoek van Verschelden naar de leefwereld van kinderen en jongeren: 'De meerderheid van de 10- en 15-jarigen vermelden hun huisdier wanneer ze het hebben over degenen die "thuis" wonen' (Verschelden, 2000: 66).

9 In de literatuur wordt dit ook wel 'antropomorfisme' genoemd. Over dit antropomorfisme wordt veel gediscussieerd. Feit is dat het voor mensen vaak al moeilijk is om zich in hun medemensen te verplaatsen, laat staan in de belevingswereld van dieren, die ontologisch aanzienlijk verschillen van mensen. Er zijn dan ook wetenschappers die antropomorfisme een vorm van 'antropocentrisme' vinden: het eigene van het dier wordt immers ontkend door het vanuit menselijke eigenschappen betekenissen toe te kennen. Daarnaast zijn er echter ook wetenschappers die een meer milde houding ten aanzien van antropomorfisme aannemen. Mensen delen immers een groot gedeelte van hun genetisch materiaal - dus ook neurologisch materiaal met andere (zoog)dieren. De kloof tussen mens en dier is dus niet zo groot. Dat betekent dat de belevingswereld van dieren en mensen wellicht toch overeenkomsten vertonen (Raes, 2001: 251-252). 
moment behoefte aan hebben. Dat maakt het huisdier tot een voortreffelijke kameraad. Het huisdier kan immers geen weerwoord geven en kan ons of ons gedrag ook niet veroordelen. ${ }^{10}$

Vooral dit laatste - het niet veroordelen van mensen en hun gedrag - maakt het dier aantrekkelijk voor justitiabelen. Een goed voorbeeld hiervan is te vinden in Forensisch Psychiatrisch Centrum 'Veldzicht' in Balkbrug. In deze justitiële inrichting voor de verpleging van terbeschikkinggestelden staat ook een boerderij, waar sinds tien jaar met paarden wordt gewerkt. Volgens sociaal-pedagogisch werker en initiatiefnemer van het paardenproject, de heer De Vrome, bestaat een aanzienlijk deel van de populatie van 'Veldzicht' uit patiënten die eerder in andere inrichtingen in behandeling zijn geweest. Wanneer deze patiënten naar 'Veldzicht' worden overgeplaatst, zijn zij vaak uitgekeken op behandelingen, therapeuten en hulpverleners. Het wordt dan moeilijk voor behandelaars om met mensen uit deze groep contact te krijgen en een dusdanige relatie op te bouwen, waarin een therapie gestalte kan krijgen. Volgens De Vrome wordt dat proces echter versoepeld door deze patiënten met paarden te laten werken (Janssen B, 2000: 188).

\section{Verbetering van de sfeer in de inrichting}

Het spreekt voor zich dat wanneer het psychisch welbevinden van gedetineerden verbetert, dit ook ten goede komt van de sfeer in de inrichting. In de literatuur zijn hiervan duidelijke voorbeelden te vinden. In 1975 begon een maatschappelijk werker in een Amerikaanse gevangenis met het inzetten van kleine dieren - zoals parkieten en vissen - als beloning voor goed gedrag. Hoewel de gedetineerden, die aan dit project meededen, gezien hun gedrag nog niet in aanmerking kwamen voor terugplaatsing in de samenleving, bleek wel dat na de introductie van kleine huisdieren het aantal vechtpartijen en zelfdodingen aanzienlijk afnam. Toen het project al enige tijd liep werd een onderzoek uitgevoerd waarbij gedetineerden met huisdieren vergeleken werden met een controlegroep zonder dieren. Opnieuw werd een afname van

\footnotetext{
${ }^{10}$ Wat wij dus denken over de gedachtewereld van dieren, zegt dus eigenlijk meer over onszelf: als iemand beweert dat een dier zijn enige vriend is, dan zegt ons dat eigenlijk niet zoveel over de aard of het karakter van het dier, maar meer over het mens- en wereldbeeld van diegene die deze uitspraak doet. In de Engelse literatuur wordt dit ook wel de 'pet trap' genoemd. Daarmee wordt bedoeld dat sommige mensen zo opgaan in het wel en wee van hun huisdieren dat zij als het ware alle belangstelling voor hun medemensen verliezen (Raes, 2001: 248).
} 
vechtpartijen en zelfdodingen geconstateerd. Daarnaast bleek ook dat het medicijngebruik onder gedetineerden met huisdieren de helft lager was in vergelijking met de controlegroep (Beck \& Katcher, 1983: 181; Council for Science and Society, 1988: 34-35; Moneymaker \& Strimple, 1991: 139140).

Eind jaren zeventig werd aan de Universiteit van Washington de 'PeoplePet-Foundation' (PPF) opgericht. Deze instelling stelde zich tot doel na te gaan hoe mensen hun voordeel zouden kunnen doen met het gezelschap van dieren. In het begin van de jaren tachtig zocht PPF contact met het gevangeniswezen en ontstond er een aantal pilot-projecten. Eén van die programma's bestond uit het aanbieden van een lesprogramma over de verzorging van honden. Daarbij werd ook stil gestaan bij de mogelijkheden op de arbeidsmarkt voor bijvoorbeeld dierenartsassistenten, hondentrimmers- en trainers. De gedetineerden werden in de gelegenheid gesteld om de kennis uit de lessen reeds in de detentie in de praktijk te brengen: door de docenten werden honden in de inrichting gebracht. Eén van de gunstige bijwerkingen van het contact tussen gedetineerden en honden was dat ook het contact tussen gedetineerden en personeel aanzienlijk verbeterde. De indruk ontstond dat gedetineerden die aan dit project meededen, milder werden en zich meer coöperatief naar het personeel opstelden (Hines, 1983: 10). Vandaag de dag zijn er in het Amerikaanse gevangeniswezen tientallen projecten die zich tot doel stellen om in detentie gedetineerden op te leiden tot dierentrainer. Volgens berichten op internet zijn deze programma's zeer succesvol: praktisch alle deelnemers vinden na detentie een baan en de recidive zou nul procent zijn. Helaas is niet duidelijk om hoeveel deelnemers het gaat en hoe de recidive gemeten is. Bij de beoordeling van deze projecten blijft dus voorzichtigheid geboden (Janssen B, 2000: 187-188).

Samenvattend kan gesteld worden dat uit verschillende voorbeelden in de literatuur blijkt dat niet alleen het psychisch welbevinden van gedetineerden verbetert, maar dat ook de relaties tussen gedetineerden onderling en tussen gedetineerden en het personeel verbeteren. Ter illustratie van dit alles een casus. 
Casus: de tuin van de heer Peters

De heer Peters ${ }^{11}$ is veroordeeld tot een levenslange vrijheidsstraf. Hij verblijft al meer dan tien jaar in een penitentiaire inrichting in het noorden van het land. Een aantal jaren na binnenkomst in deze instelling begon hij op de luchtplaats met het verbouwen van groente zoals peulen, paksoi en spinazie. Dit project hield echter maar een paar maanden stand omdat op de luchtplaats ook veel gevoetbald werd en iedereen in principe zo door zijn moestuin kon lopen. Vervolgens kwam de heer Peters zelf met het idee om een tuin aan te leggen. Omdat hij in deze inrichting bekend staat als een modelgedetineerde, werd hij door de directie in de gelegenheid gesteld om dit plan daadwerkelijk uit te voeren. Op een apart stuk van het terrein van de inrichting begon de heer Peters met het aanleggen van zijn tuin. Om in deze tuin te komen, moest hij bij het personeel een sleutel vragen. De tuin was in principe niet voor andere gedetineerden toegankelijk. De heer Peters genoot hiervan: 'in die tuin kon ik me tenminste eens terugtrekken uit de wereld van de gevangenis. Ik had eindelijk het idee dat ik een stukje voor me zelf had. Verder keek ik ook altijd uit hoe de tuin zich verder ontwikkelde; hoe doen de planten het? Hoe gaat het met de kippen ${ }^{12}$ en de vissen in de vijver? Daar kikkerde ik enorm van op.' Door zich op de tuin te richten, had hij het gevoel dat hij zijn tijd zinvol besteedde. Zo volgde hij onder meer een schriftelijke cursus over tuinieren - voor de detentie had hij namelijk nooit iets op dit gebied gedaan, zodat hij aanvankelijk vrij weinig wist over de aanleg en het onderhoud van een tuin - en besteedde hij veel energie aan het verbeteren van de structuur van de grond. Niet alleen de heer Peters, maar ook het personeel en de medewerkers in de inrichting waren enthousiast over de tuin. Zo nam bijvoorbeeld één van de directieleden zo nu en dan stekjes van planten en vissen uit zijn eigen tuin mee. Enkele PIW'ers voorzagen hem regelmatig van paarden- en/of koemest.

Helaas moest deze tuin wijken in verband met nieuwbouwplannen op het terrein van de instelling. Gelukkig werd de heer Peters in de gelegenheid gesteld om op een andere plek een nieuwe tuin aan te leggen. In deze tuin kreeg hij opnieuw de kans om dieren te gaan houden. Aanvankelijk - al bij de aanleg van de eerste tuin - zag de directie om hygiënische redenen de aanwezigheid van kippen niet zo zitten: men was bang dat door de kippen ongedierte op het terrein zou verschijnen. Uiteindelijk werd er echter toch

${ }^{11}$ Omwille van de privacy is deze naam gefingeerd.

${ }^{12}$ Voor meer informatie over de met name sociale waarde voor mensen van het houden van raskippen, zie: Mombarg, 2000. 
groen licht gegeven en werd door toedoen van het personeel een mooi kippenhok geplaatst. Aan deze dieren heeft de heer Peters veel plezier beleefd. Met name op momenten dat hij zich erg gespannen voelde, vond hij troost bij deze dieren: 'op dit moment voel ik mij onder zware druk staan. Ik weet namelijk niet hoe het mijn leven verder gaat, hoe mijn toekomst eruit ziet. Voor de tweede keer ben ik bezig om gratie aan te vragen. Ik weet eerlijk gezegd niet wat ik moet doen als het deze keer weer niet lukt. Daar wil ik liever niet aan denken. Verder praat ik veel met mijn vriendin over het al dan niet krijgen van kinderen. Zij wil dat heel graag en vanwege haar leeftijd kan ze daar ook niet al te lang meer mee wachten. Maar voor me zelf weet ik dat ik niet aan kinderen wil beginnen, als ik de rest van mijn leven gedetineerd blijf. Als ik kinderen heb, dan wil ik ze namelijk ook op zien groeien en een actieve vader zijn. Dat kan ik voor mijn gevoel niet als ik gedetineerd ben. Door deze problemen slaap ik 's nachts slecht. Ik pieker voortdurend. Maar als ik dan weer in de tuin kom en ik zie hoe de kuikentjes groeien en hoe goed mijn planten het doen, dan geeft me dat hoop. Dan weet ik dat het leven op de een of ander manier toch door gaat en met die gedachte troost ik mij.' Een bijkomend voordeel van de aanwezigheid van dieren bleek de uitbreiding van de gespreksonderwerpen te zijn. ${ }^{13}$ Medegedetineerden en personeel wilden graag op de hoogte gehouden worden van het wel en wee van de kuikens en gaven graag advies over de verzorging van planten en dieren.

Helaas heeft de geschiedenis zich herhaald. In verband met bouwactiviteiten is deze tweede tuin met dieren eveneens verdwenen.

\section{Voorwaarden voor de aanwezigheid van dieren in penitentiaire inrich- tingen}

In de criminologische en penologische literatuur zijn niet of nauwelijks beschrijvingen te vinden van (succesvolle) projecten met dieren in penitentiaire inrichtingen. Dat is jammer, want aan de hand van dergelijke beschrijven zou het eenvoudiger zijn om een aantal voorwaarden te noemen waaraan dergelijke projecten moeten voldoen, willen zij succesvol zijn. Opvallend is dat ook in de meer 'veterinaire' literatuur weinig relevante informatie - zo-

${ }^{13}$ In detentie is het aantal gespreksonderwerpen vaak beperkt: de meest genoemde thema's zijn seks, drugs en voorvallen in de inrichting (Janssen A, 2000: 97). 
als projectbeschrijvingen en evaluatiestudies - te vinden is, die goed van pas zou komen bij de opzet van deze projecten. De weinige artikelen die ik gevonden heb, zijn vaak van de hand van enthousiaste 'dierenliefhebbers', die met veel genegenheid verslag uitbrengen over programma's met dieren in detentie: 'het blijft echter jammer dat we bij wijze van spreken meer aan de weet komen van de deelnemende dieren dan van de gedetineerden' (Janssen B, 2000: 189-190). Toch wil ik hier een poging wagen en een aantal voorwaarden formuleren, waaraan mijns inziens voldaan moet zijn om het verblijf van dieren in penitentiaire inrichtingen voor zowel mens als dier prettig te laten zijn.

\section{Gebouwelijke voorzieningen}

Tamelijk voor de hand liggend is dat voor het houden van dieren in detentie aan een aantal ruimtelijke eisen voldaan zal moeten worden. Een en ander is natuurlijk afhankelijk van het soort dier en het aantal dieren. Hierbij spelen niet alleen hygiënische motieven een rol, maar gaat het natuurlijk ook om het welzijn van het dier. Het is evident dat met name binnen bestaande penitentiaire inrichtingen bijvoorbeeld niet zomaar een struisvogelfarm of een stoeterij kan worden opgezet. Dergelijke projecten zijn wellicht beter te realiseren in nieuw te bouwen inrichtingen. ${ }^{14}$

\section{Selectie van gedetineerden}

Het is nog maar de vraag of in principe alle gedetineerden geschikt zijn voor het houden van dieren. Helaas zijn in de literatuur nauwelijks selectiecriteria voor gedetineerden beschreven, maar soms werd wel terloops genoemd dat personen waarvan bekend is dat zij in het verleden gewelddadig gedrag hebben vertoond, zijn buiten gesloten van deelname aan projecten, waarin het contact met dieren een belangrijke rol speelde.

\footnotetext{
${ }^{14}$ In detentie is het tot dusver toegestaan kleine vogels en zoetwatervissen te houden. Het aquarium mag niet groter zijn dan $40 \mathrm{~cm}$. x $25 \mathrm{~cm}$. x $30 \mathrm{~cm}$. Een vogelkooi mag niet groter zijn dan $35 \mathrm{~cm}$. x $35 \mathrm{~cm}$. x $50 \mathrm{~cm}$. Er mogen maximaal twee vogels gehouden worden en de vogels mogen niet groter zijn dan $10 \mathrm{~cm}$. In artikel 45 van de PBW is het bezit van voorwerpen geregeld. Een directeur mag echter besluiten om voorwerpen te weren omdat zij bijvoorbeeld de gezondheid in gevaar brengen. Onder deze 'voorwerpen' vallen ook planten en dieren.
} 
Verder blijkt dat deelnemers doorgaans zonder pardon van verdere participatie worden buitengesloten, wanneer zich gevallen van dierenmishandeling hebben voorgedaan. Dit schijnt echter weinig voor te komen (Janssen, 2000 B: 187- 188). ${ }^{15}$ De vraag blijft echter of alle gedetineerden met een gewelddadig verleden buiten moeten worden gesloten. Het paardenproject in 'Veldzicht' geeft aan dat juist het contact met de 'zware' populatie terbeschikkinggestelden - waaronder zich wellicht ook plegers van gewelddelicten zullen bevinden - juist verbetert. Hoewel voorzichtigheid geboden blijft, is zonder meer uitsluiten wellicht niet nodig. Vanuit het welzijn van het dier geredeneerd lijkt het mij zonder meer onverantwoord om diegenen, waarvan bekend is dat zij zich in het verleden aan dierenmishandeling hebben schuldig gemaakt, deel te laten nemen.

${ }^{15}$ Interessant is dat in de literatuur een relatie wordt verondersteld tussen dierenmishandeling en andere vormen van geweld. Dit wordt ook wel de 'cruelty link' genoemd en werd reeds in de dertiende eeuw door Thomas Van Aquino naar voren gebracht. Ook Kant veronderstelde dat het hart van een mens beoordeeld kan worden door te kijken hoe hij of zij met dieren omgaat. Kant kon het dan ook waarderen dat slagers en mensen die in een slachthuis werkten in Engeland geen plaats konden nemen in een jury. Door hun wreedheid jegens dieren werden zij niet als 'menselijk' beschouwd. Locke onderschreef die mening en wees erop dat goed op kinderen gelet moest worden, die zich schuldig maakten aan dierenmishandeling. Hij vreesde namelijk dat wanneer een kind eenmaal gewend was om een dier te maltraiteren, hij of zij gemakkelijk de overgang zou maken naar het mishandelen van mensen. Met name in Groot-Brittannië en de Verenigde Staten is de laatste tien jaar weer veel aandacht besteed aan de relatie tussen dierenmishandeling en andere vormen van geweld. In deze landen zijn bijvoorbeeld dierenbeschermingsorganisaties gaan samen werken met instellingen die zich bezig houden met de opvang van mishandelde vrouwen en kinderen. Dierenmishandeling wordt vaak gezien als een indicator van geweld en mishandeling binnen het gezin (Cazaux, 2001: 280-289). 
Een ander selectiecriterium dat zo nu en dan in de literatuur genoemd wordt, is de duur van het strafrestant (Janssen, 2000 B: 187-188). De duur van het strafrestant gaat met name een rol spelen, wanneer het houden van dieren verbonden wordt aan een opleidingsprogramma. De duur van het verblijf in detentie hoeft echter niet noodzakelijkerwijs een belemmering te zijn. Binnen het penitentiair programma zijn er bijvoorbeeld mogelijkheden om ook extramuraal aan opleiding en werkervaring gestalte te geven.

Tot slot moet er ook gedacht worden aan de culturele component. Uit het onderzoek naar huisdieren blijkt, dat de enorme populariteit van huisdieren met name een westers verschijnsel is, dat sterk is opgekomen na de Tweede Wereldoorlog (Serpell, 1986: 84; Raes, 2001: 248). Alle goede bedoelingen ten spijt moet er rekening mee worden gehouden dat een niet-westerling wellicht niet zit te wachten op de aanwezigheid van een hond of kat in de inrichting ter 'verzachting' van de detentieperiode.

\section{Slot}

In dit artikel heb ik in vogelvlucht uit de doeken gedaan hoe dieren voor therapeutische doeleinden in instellingen zoals penitentiaire inrichtingen zouden kunnen worden ingezet. Daarbij heb ik met name gebruik gemaakt van Amerikaanse voorbeelden, waarbij ik aangegeven heb dat er helaas weinig degelijke evaluatiestudies zijn verricht. Uit de strekking van deze tekst is het de lezer wellicht duidelijk geworden dat ik zelf desalniettemin gecharmeerd ben van dier-therapeutische projecten. Dat neemt echter niet weg dat ik ook een belangrijke kanttekening wil plaatsen bij de inzet van dieren in instellingen. Wij weten nog steeds te weinig over de interactie tussen mensen en dieren. Er zijn wel degelijk aanwijzingen dat het houden van dieren een gunstige invloed heeft op onze fysieke en psychische gezondheid. Het inzetten van dieren is echter geen wondermiddel. Eerder gaf ik al aan dat het dier vaak zo'n gewaardeerde vriend is omdat het niets kan zeggen en ons dus ook niet kan tegenspreken. In deze 'kracht' - het niet kunnen spreken schuilt tevens de beperking van het dier als therapeut. Wie daadwerkelijk iets aan zijn eigen problemen wil doen, zal toch zijn gedrag - in het heden en verleden - onder de loep moeten nemen. Als daarbij de hulp nodig blijkt te zijn, dan zal die toch van een 'menselijke' therapeut moeten komen. Met andere woorden, dieren zijn dus niet zozeer de oplossing, maar kunnen beter gezien worden als een 'facilitator'. Door contact met dieren kunnen mensen voorzien in hun affectieve behoeften. Dat komt het psychisch welbevinden ten goede, waardoor een betere basis voor een therapeutische behandeling ontstaat. 
Verder is het wenselijk om niet alleen naar de Amerikaanse ervaringen te kijken. Ook in de Nederlandse (geestelijke) gezondheidszorg worden steeds vaker dieren 'ingezet'. Een van de belangrijkste exponenten van deze trend is de 'zorgboerderij'. Inmiddels bestaan er ook zorgboerderijen voor verslaafden, (ex-) gedetineerden en mensen uit de 'overlast-categorie'. Wellicht brengt evaluatie en een goede inventarisatie van dergelijke projecten nieuwe kennis en inzichten met zich mee, die op het penitentiaire veld kunnen worden toegepast. 


\section{Literatuur}

1. Beck, A. \& Katcher, A., Between pets and people. The importance of animal companionship, New York: G.P. Putnam's Sons: 1983.

2. Bouckaert, M., Het werk van Chakka: preventie, educatie en de positieve waarden omtrent de relatie tussen mensen en honden, in: $\mathrm{Ca}-$ zaux, G. (red.), Mensen en andere dieren. Hun onderlinge relaties meervoudig bekeken, Leuven/Apeldoorn: Garant, 2001: 299-315.

3. Cazaux, G., Verband tussen geweld jegens dieren en geweld jegens mensen, in: Cazaux, G. (red.), Mensen en andere dieren. Hun onderlinge relaties meervoudig bekeken, Leuven/Apeldoorn: Garant, 2001: 279-296.

4. Council for Science and Society, Companion animals in society, Oxford: Oxford University Press, 1988.

5. Franklin, Animals in modern culture. A sociology of human-animal relations in modernity, Londen: Sage Publications: 1999.

6. Hines, L.M., Pets in prison: a new partnership, in: California Veterinarian, nr. 5, 1983: 7-17.

7. A) Janssen, J., Laat maar zitten. Een exploratief onderzoek naar de werking van de korte vrijheidsstraf, Den Haag: Boom Juridische Uitgevers, 2000.

8. B) Janssen, J., Bij de beesten af. Huisdieren van en voor gedetineerden, in: Proces, nr. 11/12, 2000: 186-191.

9. Moneymaker, J.M. \& Strimple, E.O., Animals and inmates: a sharing companionship behind bars, in: Journal of Offender Rehabilitation, vol. 16 (3/4), 1991: 133-152.

10. Mombarg, B., Houden van kippen. Een historisch-sociologische analyse van de raspluimveeteelt, Assen: Van Gorcum, 2000.

11. Poe, E. A., De zwarte kater, in: Poe, E. A., Verhalen. Met een voorwoord van Jan Wolkers, Amsterdam/Antwerpen: Uitgeverij Contact, 2000: 492-502.

12. Raes, K., Omgaan met gezelschapsdieren als ethisch probleem, in: Cazaux, G. (red.), Mensen en andere dieren. Hun onderlinge relaties meervoudig bekeken, Leuven/Apeldoorn: Garant, 2001: 245-261.

13. Serpell, J., In the company of animals. A study of human-animal relationships, Oxford: Blackwell, 1986.

14. Serpell, J., In the company of animals. A study of human-animal relationships, Cambridge: Cambridge University Press, 1996. 
15. Sheldrake, R., Dogs that know when their owners are coming home and other unexplained powers of animals, Londen: Hutchinson, 1999.

16. Verschelden, G., Belevingsonderzoek bij kinderen en jongeren. Kinderen en jongeren over hun behoefte aan zorg Brussel: Ministerie van Cultuur, Gezin en Welzijn, 2000. 